\title{
Late Transitions and Bereaved Family Member Perceptions of Quality of End-of-Life Care
}

\section{Running Title: Late Transitions and Quality of End-of-Life Care}

Lena K. Makaroun, MD, $\mathrm{MS}^{1,2}$, Joan M. Teno, MD, $\mathrm{MS}^{3,4}$, Vicki A. Freedman, $\mathrm{PhD}^{5}$, Judith D. Kasper, $\mathrm{PhD}^{6}$, Pedro Gozalo, $\mathrm{PhD}^{4,7}$ and Vincent Mor, $\mathrm{PhD}^{4,7}$.

1. Health Services Research and Development, VA Puget Sound Healthcare System

2. Division of Gerontology and Geriatric Medicine, University of Washington

3. Provisional Oregon Health and Science University

4. Department of Health Services, Policy, and Practice, Brown University School of Public Health

5. Institute for Social Research, University of Michigan

6. Department of Health Policy and Management, Johns Hopkins Bloomberg School of Public Health

\section{Providence Veterans Administration Medical Center}

Impact Statement: We certify that this work is novel. While prior literature has demonstrated that healthcare transitions for a more general population are associated with certain markers of poor quality of care, this study is the first to demonstrate that transitions for actively dying patients in the last three days of life are associated with poor quality of care as reported by bereaved family and friends. This study uses important patient-centered outcomes, and these findings have high impact implications for improving care for a vulnerable population.

Funding sources: The National Health and Aging Trends Study (NHATS) is funded by the National Institute on Aging (grant number NIA U01AG032947) through a cooperative agreement with the Johns Hopkins Bloomberg School of Public Health. Drs. Kasper, Freedman and Mor are NHATS investigators and receive support through this grant. Dr. Teno received funding from the Retirement Research Foundation in the analysis of the National Health and Aging Trends Study.

Corresponding Author:

Lena K. Makaroun, M.D.

VA Puget Sound Health Care System

1660 S. Columbian Way, S-152

Seattle, WA 98108

Telephone: (206) 277-1548, Fax: (206) 768-5309

Twitter: @LenaKMakaroun

E-mail: Makaroun@uw.edu

Abstract word count: 297

Body word count: 3,068

Number of Tables: 3, Number of Figures: 1

This is the author manuscript accepted for publication and has undergone full peer review but has not been through the copyediting, typesetting, pagination and proofreading process, which may lead to differences between this version and the Version of record. Please cite this article as doi:10.1111/jgs.15455. 


\section{Abstract}

Background/Objective: Health care transitions in the last three days of life have increased in the United States. We aimed to examine associations between late transitions and bereaved family members' and friends' assessment of the quality of endof-life care.

Design: National Health and Aging Trends Study (NHATS), a prospective cohort of Medicare enrollees age $\geq 65$.

Setting: United States, all sites of death.

Participants: Family members and close friends of decedents from NHATS rounds 2-6 $(\mathrm{N}=1,653$; weighted 6.0 million Medicare deaths).

Exposure: Medicare decedents' experiencing a transition between any location and a healthcare institution in the last three days of life.

Measurements: Multivariable logistic regression with survey weights examined the association between having a late transition and reports of perceived unmet needs for symptom management, spiritual support, concerns with communication, and overall care quality (QOC). 
Results: Seventeen percent of decedents experienced a late transition. Bereaved respondents for decedents experiencing late transitions were more likely to report that the decedent was treated without respect $(21.3 \% \vee 15.6 \%$; adjusted odds ratio (AOR) $1.59,95 \%$ confidence interval $(\mathrm{Cl}): 1.09-2.33)$, had more unmet needs for spiritual support (67.4\% v 55.2\%; AOR 1.48, 95\% Cl: $1.03-2.13)$, and were more likely to report they were not kept informed about patients' condition (31.0\% v 20.9\%; AOR 1.54 , $95 \% \mathrm{Cl}: 1.07-2.23)$. Bereaved respondents were less likely to rate QOC as excellent when there was a late transition (43.6\% v 48.2\%; AOR 0.79, 95\% Cl: $0.58-1.06)$. Subgroup analyses of those experiencing a transition between a nursing home and hospital ( $13 \%$ of all late transitions) revealed such transitions to be associated with even worse QOC.

Conclusion: Transitions in the last three days of life are associated with more unmet needs, higher rate of concerns, and lower rating of quality of care, especially when that transition is between a nursing home and hospital.

Key Words: Healthcare transitions, quality of care, End-of-Life care

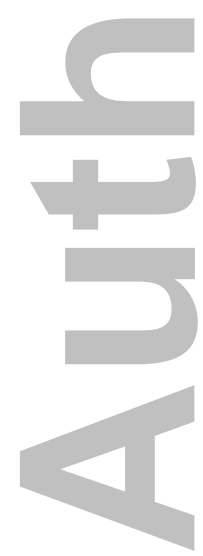




\section{Introduction}

Health care transitions have been shown to put patients and their family at risk for fragmentation in care, medical errors and unnecessary diagnostic testing. ${ }^{1-4}$ Previously, in a study of nursing home patients, Gozalo and colleagues ${ }^{5}$ proposed three transitions as potentially burdensome: 1) healthcare transitions in the last three days of life; 2) lack of continuity in nursing homes post-hospitalization in the last 90 days of life; 3) multiple hospitalizations in the last 90 days of life for expected complications while dying. They showed that nursing home residents in regions of the country with high rates of these transitions were more likely to have a feeding tube, had increased intensive care unit (ICU) utilization in the last month of life and were more likely to suffer a stage IV decubitus ulcer. Despite evidence that burdensome transitions at the end of life may be associated with markers of poor quality of care, the number of late healthcare transitions for patients at the end of life has been increasing over the past decade. $^{6}$

Teno and colleagues have studied healthcare transitions in the last three days of life as a marker of poor quality of care based on expert opinion and prior study of persons dying in nursing homes. ${ }^{7}$ No study has yet shown, however, whether bereaved family members report different perceptions of the quality of care when their family member has a transition in the last three days of life. We hypothesize that numerous problematic issues may arise during late transitions, such as family having to meet an unfamiliar care team, delays in needed medication for symptom management and breakdown in communication during a vulnerable time for patients. Patient reported outcomes provide a reliable and valid consumer perception of quality of care at the end 
of life ${ }^{8-10}$ While patients at the end of life are often too sick or debilitated to participate in interviews, family members can reliably report on their loved one's experience. ${ }^{11}$ Bereaved family member survey tools have been developed and validated, ${ }^{12,13}$ and caregiver interviews have been shown to correlate with quality of care at the end of life. ${ }^{13-16}$

The primary aim of this study was to examine the relationship between healthcare transitions in the last three days of life (referred to here as "late transitions") and end-of-life quality of care (QOC). Information from bereaved family member surveys of deceased participants from the National Health and Aging Trends Study (NHATS) was examined to analyze if health care transitions in the last three days of life to locations other than home were associated with bereaved family member perceptions of unmet needs, problems in communication and concerns with quality of care. We also sought to identify if there were differences in perceived quality when the transition was between a hospital and a nursing home.

\section{Methods}

Study Population

NHATS is a nationally-representative sample of Medicare enrollees in the US age 65 or older that started in $2011 .{ }^{17}$ NHATS utilized a stratified three-stage sample design, and oversampled persons at older ages and Black individuals. ${ }^{18}$ Beginning in round 2, a Last Month of Life (LML) interview was introduced and conducted with a proxy respondent to obtain information on the end-of-life experience of participants who died between rounds. The proxy respondent was usually a family member but could also be a close friend or other person with intimate knowledge of the participant. As part 
of the LML interview, proxy respondents were asked how familiar they were with the decedent's daily routine. To be included in the analysis, proxy respondents had to answer that they were at least "somewhat familiar" with the decedent's daily routine. We examined LML surveys for participants from 2012-2016 (rounds 2-6). Unweighted response rates for the LML interview in rounds 2-6 were between $94.1 \%$ and $96.4 \%{ }^{19}$ Out of a total of 2,212 decedents with completed LML interviews, 1,653 with a family or friend proxy who was at least "somewhat familiar" with the decedent's daily routine were included in the analysis (weighted 6.0 million deaths).

\section{$\underline{\text { Measures }}$}

The main exposure of interest was having had a healthcare transition in the last three days of life. Proxy respondents were not asked directly whether or not the decedent had a late transition. Rather, those who reported that the decedent died somewhere other than home were asked how long they had been at that location prior to dying. Decedents with a duration of $\leq 3$ days were considered as having the exposure. Options for place of death included their own or another's home, nursing home, hospital or palliative care unit/hospice residence. For decedents who died places other than home, respondents were also asked where the decedent stayed just before the place of death. Options for location prior to death included the decedent's own or another's home, nursing home, hospital or hospice residence. Because late transitions to home were not captured in the LML interview, they are not represented in the analysis. If a decedent experienced a late transition from a nursing home to a hospital or from a hospital to a nursing home, they were considered to have an institution-toinstitution transition. 
The main outcome of interest was perceived quality of end-of-life care as reported by the proxy (bereaved LML respondent). Items included unmet needs (e.g. for pain management, dyspnea management, anxiety and sadness, and spiritual support) and interactions with the care team (e.g. how often the decedent was treated with respect, adequacy of individual and family involvement in care decisions, how often family was kept informed of the decedent's condition, and whether the decedent received care that he/she would not have wanted). For unmet needs, those who did not experience a certain symptom in the last month of life were considered to have no unmet needs for that symptom. LML respondents were also asked how they would rate the decedent's overall quality of care in the last month of life (excellent, very good, good, fair, or poor) (see Supplementary Table S1 for specific questions).

Basic demographic information including age and race/ethnicity was available for each decedent. During initial enrollment in NHATS and with each subsequent round of interviews, participants reported physician-diagnosed medical problems. We compared decedents by the presence of six major medical comorbidities (including both prevalent cases in 2011 and incident cases during the study period): heart disease, diabetes mellitus, lung disease, stroke, dementia and cancer. To measure functional status, decedents who got out of bed only "some days", "rarely" or "never" in the last month of life and those who were "never" alert during the last month of life were classified as having lower functional status. Information on the relationship of the proxy respondent for each decedent was collected and reported.

\section{$\underline{\text { Statistical Analysis }}$}


A binary variable for the presence of a late transition to locations other than home was created. Similarly, we created an indicator for having experienced an institution-to-institution transition that reflected a transition between an acute care hospital and nursing home. We fit logistic regression models to study the association of having a late transition with each different measure of quality of care. In addition to unadjusted models, models adjusted for age, sex, race, relationship of bereaved respondent, functional status and comorbidities were included in the multivariable model. All analyses incorporated survey weights to account for the complex survey design of NHATS.

Decedents who had trouble getting out of bed in the last month of life likely represent a sub-population of our sample that was sicker and more functionally impaired. To explore any differences in this sub-population, we performed a sensitivity analysis fitting adjusted logistic regression models on the subset of the sample who had difficulty getting out of bed in the last month of life. We performed an additional sensitivity analysis restricting to those respondents who were "very familiar" with the decedent's routine.

All analyses were performed using Stata 14.2 statistical package. As we relied on de-identified data, the Brown University Institutional Review Board determined that this project did not qualify as human subjects research.

\section{Results}

\section{Decedent Characteristics}

Table 1 shows baseline characteristics of decedents in the cohort by late transition status. Overall, the distributions of race, age, and relationship of proxy 
respondent were similar between the two groups. A higher percentage of those not experiencing a late transition had difficulty getting out of bed in the last month of life $(49.5 \%$ vs. $23.2 \%, p<0.001)$. The group who experienced a late transition had less heart disease $(7.0 \% \vee 10.9 \%, p=0.03)$ and less cancer $(14.0 \% \vee 17.7 \%, p=0.04)$ compared to the group that did not experience a late transition (see Table 1). The most common type of late transition (47.4\%) was from home to the hospital (see Supplementary Table S2 for all transition types).

\section{Any Transition in Last Three Days of Life and Quality of Care}

Seventeen percent of decedents ( $N=272$, weighted $N=1.0$ million) experienced a late transition to a location other than home. Having experienced a late transition was associated with certain markers of worse quality of care at the end of life (Table 2). Respondents reported more unmet needs for spiritual support when the decedent experienced a late transition (AOR 1.48, 95\% Cl: $1.03-2.13$ ). Decedents experiencing a late transition were also more likely to not always be treated with respect (AOR 1.59, $95 \% \mathrm{Cl}: 1.09-2.33)$, and their families were more likely to not always be informed of their condition (AOR 1.54, 95\% Cl: 1.07 - 2.23). While not reaching conventional levels of statistical significance $(p<0.05)$, for those who experienced a late transition there was a pattern of being more likely to report: unmet needs for pain, dyspnea and anxiety/sadness management; receiving care not consistent with decedent goals; and having inadequate communication regarding care decisions (Table 2). Respondents of decedents who experienced a late transition were less likely to report that the overall quality of care at the end of life was excellent (AOR $0.79,95 \% \mathrm{Cl}: 0.58-1.06$ ), though this finding did not reach $p=0.05$. In sensitivity analyses examining the subset of 
decedents who had difficulty getting out of bed and the subset of respondents who were "very familiar" with decedent routine, similar patterns were observed (Supplementary Tables S3 and S4).

Institution-to-Institution Transition in the Last Three Days of Life and Quality of Care

Thirteen percent of late transitions were between a hospital and a nursing home ( $N=42$, weighted $N=131,731)$. Having experienced an institution-to-institution late transition (from nursing home to hospital or from hospital to nursing home) in the last three days of life was associated with worse perceived quality of care for several outcomes compared to having no late transition or having a non-institution late transition (Figure 1). Bereaved respondents reported more unmet needs for anxiety and sadness management when the decedent experienced an institution-to-institution late transition (AOR 3.66, 95\% Cl: $1.34-10.02$ ). Decedents experiencing an institution-to-institution late transition were also more likely to receive care inconsistent with their goals (AOR $3.44,95 \% \mathrm{Cl}: 1.75-6.77)$ and receive inadequate communication about care decisions. (AOR 3.37, 95\% Cl: $1.45-7.79$ ). While not reaching conventional levels of statistical significance, for those who experienced a late institution-to-institution transition there was a pattern of higher reports of: unmet needs for pain and dyspnea management; decedent not always being treated with respect; and family not being always informed of decedent condition (Table 3 ). When qualitatively compared to the adjusted odds ratios for any late transition in Table 2, the effect size of an institution-toinstitution late transition on quality of care was of higher magnitude across most outcome measures.

\section{Discussion}


Using a nationally representative sample of older Americans, we found that bereaved family members or close friends report more unmet needs, higher rates of concerns, and lower rating of the quality of care when there is a health care transition in the last three days of life. Experiencing a late transition between a nursing home and hospital was associated with even lower quality of care; only $32.1 \%$ of those who experienced that transition said care was excellent compared to $48.2 \%$ who did not have a late transition. Despite the observed rise since 2000 in the number of Americans experiencing healthcare transitions at the end of life, ${ }^{6}$ little is known about how such transitions affect perceptions of the quality of care received. Prior qualitative studies of both patients and their caretakers have revealed problems in communication, difficulty contacting providers when needed and lack of needed information during care transitions. ${ }^{20-23}$ Previous work on transitions, however, has not dealt with a population of actively dying persons, who often have more complex medical and social needs. This population was the focus of this study. Increasing attention and interventions are needed to improve healthcare transitions in actively dying persons.

While many of the confidence intervals for the adjusted odds ratios in our study crossed one, the effects were consistently in the direction hypothesized, and the effect sizes, particularly for the institution-to-institution transitions, were large. Numerous critiques of relying on p-values for inference have been proposed,$^{24}$ and we assert that focusing on estimation and presenting a measure of uncertainty via confidence intervals, as others have suggested, ${ }^{25}$ allows us to draw relevant conclusions from these data. Our study found a high prevalence of unmet needs and inadequate communication among those who experienced a late transition, with only $44 \%$ reporting 
excellent quality of end-of-life care. These problems were more prevalent when a decedent experienced a late transition in either direction between a hospital and nursing home. Although a 4 percentage point difference in reported excellent QOC between those who did and did not experience a late transition (44\% v 48\%) may seem small, recent studies have shown that even very small differences in patient reported quality ratings can translate into meaningful differences in disenrollment from health plans ${ }^{26}$ or willingness to recommend hospice programs. ${ }^{27}$ With nearly one in five Americans in this study experiencing a late transition in the last three days of life, and $13 \%$ of these cases experiencing a transition between a hospital and a nursing home, this is a subpopulation of vulnerable patients where important opportunities exist to improve the quality of care.

Numerous factors may be involved in making transitions between hospitals and nursing homes particularly detrimental at the end of life. Actively dying persons often have complex medical problems and numerous needs for symptom management. When transitioning between hospitals and nursing homes, communication of care plans may be incomplete, prescribing of pain medications may be delayed leading to poorer symptom control, and family members and patients must reacquaint with a new care team. Work by Wetle et al. suggests that family members of individuals dying in nursing homes often feel unprepared by nursing home staff about what to expect in the dying process, ${ }^{28}$ that the needs of their dying family members are inadequately met, and that nursing home staff are not sufficiently trained to provide appropriate end-of-life care, ${ }^{29}$ creating increased burden on patients and families to provide care through the dying process. ${ }^{30}$ While there has been extensive work on interventions to improve healthcare 
transitions experienced by all persons, for example the Transitional Care Intervention from Coleman and colleagues ${ }^{31,32}$ and the Transitional Care Model from Naylor and colleagues ${ }^{33}$ more focused research is needed to understand how to improve care transitions for actively dying persons, particularly those focusing on late transitions between hospitals and nursing homes.

More research is needed to understand the nature of the association between late transitions and bereaved family member perceptions of end-of-life QOC. This study could not determine causality, and it is possible that experiencing a late transition may be a marker of other problematic characteristics of end-of-life care. For example, in some cases the transition may actually be welcome, but it is the care preceding or following the transition that leads to unmet needs for symptom management and poor communication with patients and families. Further studies are needed to identify subsets of actively dying patients that may benefit most from interventions to avoid late transitions when possible and improve those transitions that must occur. Prior studies have shown that different diseases may lead to variable trajectories of functional decline and death. ${ }^{34-36}$ This study did not attempt to differentiate between decedents who had different disease trajectories, and it is possible that those with more chronic illness and predictable disease course may benefit from different interventions than those with acute, precipitous declines. For example, those with acute declines may benefit from a sort of "rapid response" hospice team, specially trained and equipped to address the needs of these patients. While our sensitivity analyses showed a consistent pattern of worse perceptions of end-of-life QOC in those who likely had a more predictable decline, a useful next step would be to more accurately categorize different phenotypes 
of patients. For all patients, however, we propose that late transitions may serve as a population-based measure for quality improvement.

This study has a number of potential limitations. We analyzed bereaved family member perceptions in which respondents are asked to serve as proxies for the decedent, as well as represent their own perceptions of care (e.g. whether they were kept informed about the patient's condition). While we cannot be sure that proxy answers align with what the decedent would have reported, family member respondents have been shown to provide reliable information on the quality of end-of-life care. ${ }^{11}$ There were several limitations of the study design: 1) small sample size of the subgroup analysis of those with institution-to-institution transitions, 2) because of sample size limitations, some results suggested differences, but did not reach conventional levels of statistical significance, 3) inability to comment on causality given the observational design, and 4) the inability to identify late transitions to home. Strengths included: 1) using a nationally representative sample to analyze late transitions in a population of dying patients, 2) using bereaved family member and friend reports to obtain a patient-centric view of quality of care at the end of life, and 3) being able to identify location specific transitions that are particularly problematic (e.g. transitions specifically between nursing homes and hospitals).

In conclusion, there remains an important opportunity to improve health care transitions among persons in the last days of life, particularly when these transitions occur between hospitals and nursing homes. Numerous avenues exist to improve the care of persons experiencing transitions in the last days of life, including improved advanced care planning to avoid unnecessary transitions when able, and innovative 
communication modalities to ensure that needs and concerns of the patient and family are met in those that are appropriate.

\section{Acknowledgements}

Conflict of Interest: The authors have no conflicts to declare.

Author contributions: Makaroun, Teno, Kasper, Freedman, Gozalo, Mor: Manuscript concept, design, interpretation of data, critical revision of manuscript and final approval of version to be published. Makaroun and Teno: data analysis. Makaroun: Preparation and original writing of manuscript.

Sponsor's Role: No sponsor had a role in the design, preparation or decision to publish this manuscript.

\section{References:}

1. Boockvar K, Fishman E, Kyriacou CK, Monias A, Gavi S, Cortes T. Adverse events due to discontinuations in drug use and dose changes in patients transferred between acute and long-term care facilities. Arch Intern Med. 2004 Mar 8;164(5):545-50.

2. Field TS, Gurwitz JH, Avorn J, McCormick D, Jain S, Eckler M, et al. Risk factors for adverse drug events among nursing home residents. Arch Intern Med. 2001 Jul 9;161(13):1629-34.

3. Coleman EA. Falling through the cracks: challenges and opportunities for improving transitional care for persons with continuous complex care needs. J Am Geriatr Soc. 2003 Apr;51(4):549-55.

4. Moore C, Wisnivesky J, Williams S, McGinn T. Medical errors related to discontinuity of care from an inpatient to an outpatient setting. J Gen Intern Med. 2003 Aug;18(8):646-51.

5. Gozalo P, Teno JM, Mitchell SL, Skinner J, Bynum J, Tyler D, et al. End-of-Life Transitions among Nursing Home Residents with Cognitive Issues. N Engl J Med. 2011 Sep 29;365(13):1212-21.

6. Teno JM, Gozalo PL, Bynum JW, et al. Change in end-of-life care for medicare beneficiaries: Site of death, place of care, and health care transitions in 2000, 2005, and 2009. JAMA. 2013 Feb 6;309(5):470-7.

7. Wetle T, Teno J, Shield R, Welch L, Miller SC. End of Life in Nursing Homes: Experiences and Policy Recommendations [Internet]. Washington, DC: AARP; 2004 Nov [cited 2016 Sep 16]. Available from: http://assets.aarp.org/rgcenter/health/2004_14_eol.pdf

8. Teno JM, Lima JC, Lyons KD. Cancer Patient Assessment and Reports of Excellence: Reliability and Validity of Advanced Cancer Patient Perceptions of the Quality of Care. J Clin Oncol. 2009 Apr 1;27(10):1621-6.

9. Singer PA, Martin DK, Kelner M. Quality end-of-life care: patients' perspectives. JAMA. 1999 Jan 13;281(2):163-8.

10. Steinhauser KE, Clipp EC, McNeilly M, Christakis NA, McIntyre LM, Tulsky JA. In search of a good death: observations of patients, families, and providers. Ann Intern Med. 2000 May 
16;132(10):825-32.

11. McPherson CJ, Addington-Hall JM. Judging the quality of care at the end of life: can proxies provide reliable information? Soc Sci Med. 2003 Jan;56(1):95-109.

12. Teno JM, Casey VA, Welch LC, Edgman-Levitan S. Patient-Focused, Family-Centered End-of-Life Medical Care. J Pain Symptom Manage. 2001 Sep 1;22(3):738-51.

13. Teno JM, Clarridge B, Casey V, Edgman-Levitan S, Fowler J. Validation of Toolkit AfterDeath Bereaved Family Member Interview. J Pain Symptom Manage. 2001 Sep;22(3):752-8.

14. Teno JM, Clarridge BR, Casey V, et al. Family perspectives on end-of-life care at the last place of care. JAMA. 2004 Jan 7;291(1):88-93.

15. Wright AA, Keating NL, Ayanian JZ, Chrischilles EA, Kahn KL, Ritchie CS, et al. Family Perspectives on Aggressive Cancer Care Near the End of Life. JAMA. 2016 Jan 19;315(3):28492.

16. Wright AA, Keating NL, Balboni TA, Matulonis UA, Block SD, Prigerson HG. Place of Death: Correlations With Quality of Life of Patients With Cancer and Predictors of Bereaved Caregivers' Mental Health. J Clin Oncol. 2010 Oct 10;28(29):4457-64.

17. Kasper JD, Freedman VA. National Health and Aging Trends Study User Guide: Rounds 1, 2, 3, 4 \& 5 Final Release [Internet]. Baltimore: Johns Hopkins University School of Public Health; 2016 [cited 2017 Jun 22]. Available from: www.NHATS.org

18. Montaquila J, Freedman VA, Edwards B, Kasper JD. National Health and Aging Trends

Study Round 1 Sample Design and Selection. NHATS Technical Paper \#1 [Internet]. 2012.

Available from: www.NHATS.org

19. Kasper JD, Freedman VA. National Health and Aging Trends Study User Guide: Rounds 1-6 Beta Release. [Internet]. Baltimore: Johns Hopkins University School of Public Health; 2017 Jul [cited 2017 Sep 14]. Available from: www.NHATS.org

20. Harrison A, Verhoef $M$. Understanding coordination of care from the consumer's perspective in a regional health system. Health Serv Res. 2002 Aug;37(4):1031-54.

21. vom Eigen KA, Walker JD, Edgman-Levitan S, Cleary PD, Delbanco TL. Carepartner experiences with hospital care. Med Care. 1999 Jan;37(1):33-8.

22. Weaver FM, Perloff L, Waters T. Patients' and caregivers' transition from hospital to home: needs and recommendations. Home Health Care Serv Q. 1998;17(3):27-48.

23. Fuji KT, Abbott AA, Norris JF. Exploring care transitions from patient, caregiver, and health-care provider perspectives. Clin Nurs Res. 2013 Aug;22(3):258-74.

24. Wasserstein RL, Lazar NA. The ASA's Statement on p-Values: Context, Process, and Purpose. Am Stat. 2016 Apr 2;70(2):129-33.

25. Cumming G. The new statistics: why and how. Psychol Sci. 2014 Jan;25(1):7-29.

26. Quigley Denise D., Elliott Marc N., Setodji Claude Messan, Hays Ron D. Quantifying Magnitude of Group-Level Differences in Patient Experiences with Health Care. Health Serv Res [Internet]. $2018 \mathrm{Feb} 12 ; 0(0)$. Available from: https://onlinelibrary. wiley.com/doi/abs/10.1111/1475-6773.12828

27. Anhang Price R, Stucky B, Parast L, Elliott MN, Haas A, Bradley M, et al. Development of Valid and Reliable Measures of Patient and Family Experiences of Hospice Care for Public Reporting. J Palliat Med. 2018 Mar 20;

28. Shield RR, Wetle T, Teno J, Miller SC, Welch LC. Vigilant at the End of Life: Family Advocacy in the Nursing Home. J Palliat Med. 2010 Apr 26;13(5):573-9.

29. Wetle T, Shield R, Teno J, Miller SC, Welch L. Family Perspectives on End-of-Life Care Experiences in Nursing Homes. The Gerontologist. 2005 Oct 1;45(5):642-50.

30. Shield RR, Wetle T, Teno J, Miller SC, Welch L. Physicians "Missing in Action": Family Perspectives on Physician and Staffing Problems in End-of-Life Care in the Nursing Home. J Am Geriatr Soc. 2005 Oct 1;53(10):1651-7.

31. Coleman EA, Parry C, Chalmers S, Min S. The Care Transitions Intervention: Results of a Randomized Controlled Trial. Arch Intern Med. 2006 Sep 25;166(17):1822-8. 
32. Voss R, Gardner R, Baier R, Butterfield K, Lehrman S, Gravenstein S. The Care Transitions Intervention: Translating From Efficacy to Effectiveness. Arch Intern Med. 2011 Jul 25;171(14):1232-7.

33. Hirschman KB, Shaid E, McCauley K, Pauly MV, Naylor MD. Continuity of Care: The Transitional Care Model. Online J Issues Nurs. 2015 Sep 30;20(3):1.

34. Teno JM, Weitzen S, Fennell ML, Mor V. Dying Trajectory in the Last Year of Life: Does Cancer Trajectory Fit Other Diseases? J Palliat Med. 2001 Dec 1;4(4):457-64.

35. Lunney JR, Lynn J, Foley DJ, Lipson S, Guralnik JM. Patterns of Functional Decline at the End of Life. JAMA. 2003 May 14;289(18):2387-92.

36. Covinsky Kenneth E., Eng Catherine, Lui Li-Yung, Sands Laura P., Yaffe Kristine. The Last 2 Years of Life: Functional Trajectories of Frail Older People. J Am Geriatr Soc. 2003 Mar 26;51(4):492-8.

\section{Supplementary Appendix}

Supplementary Table S1. NHATS LML Interview Questions Regarding EOL QOC

Supplementary Table S2. Number and Proportion of All Late Transitions by Type

Supplementary Table S3. Associations Between Bereaved Family Member Perceptions of the Quality of Care and Presence of a Late Transition in the Last Three Days of Life for Those with Poor Functional Status

Supplementary Table S4. Associations Between Bereaved Family Member Perceptions of the Quality of Care and Presence of a Late Transition in the Last Three Days of Life for Decedents with Respondents "Very Familiar" with Routine

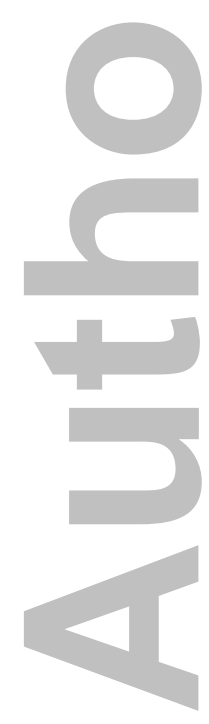


$\underline{\text { Tables }}$

Table 1. Characteristics of decedents in study population

\begin{tabular}{|c|c|c|c|}
\hline Characteristic & $\begin{array}{l}\text { Late Transition } \\
\qquad \mathrm{N}=272 \\
\text { (Weighted } \mathrm{N}=1.0 \text { million) }\end{array}$ & $\begin{array}{c}\text { No Late Transition } \\
\qquad \mathrm{N}=1381 \\
\text { (Weighted } \mathrm{N}=5.0 \text { million) }\end{array}$ & p-value \\
\hline $\begin{array}{l}\text { Race/ethnicity, no. (\%) } \\
\text { White, non-hispanic } \\
\text { Black, non-hispanic } \\
\text { Hispanic } \\
\text { Other } \\
\text { Don't know/missing }\end{array}$ & $\begin{array}{c}173(63.6) \\
59(21.7) \\
8(2.9) \\
12(4.4) \\
20(7.4) \\
\end{array}$ & $\begin{array}{c}864(62.6) \\
275(19.9) \\
69(5.0) \\
38(2.8) \\
135(9.8) \\
\end{array}$ & $\begin{array}{l}0.93 \\
0.55 \\
0.07 \\
0.15 \\
0.14\end{array}$ \\
\hline $\begin{array}{l}\text { Age at death, no. }(\%)^{\mathrm{a}} \\
\quad 65-69 \\
70-74 \\
75-79 \\
80-84 \\
84-89 \\
\geq 90\end{array}$ & $\begin{array}{l}7(2.3) \\
29(10.7) \\
36(13.2) \\
54(19.9) \\
64(23.5) \\
82(30.1)\end{array}$ & $\begin{array}{l}78(5.6) \\
112(8.1) \\
164(11.9) \\
273(19.8) \\
324(23.5) \\
430(31.1)\end{array}$ & $\begin{array}{l}0.01 \\
0.08 \\
0.33 \\
0.31 \\
0.92 \\
0.78\end{array}$ \\
\hline $\begin{array}{l}\text { Proxy Respondent, no. } \\
\text { (\%) } \\
\text { Spouse } \\
\text { Child } \\
\text { Other family } \\
\text { Friend/Non-family }\end{array}$ & $\begin{array}{c}63(23.2) \\
145(53.3) \\
38(14.0) \\
26(9.6) \\
\end{array}$ & $\begin{array}{c}302(21.9) \\
779(56.4) \\
133(9.6) \\
167(12.1) \\
\end{array}$ & $\begin{array}{l}0.41 \\
0.30 \\
0.10 \\
0.38\end{array}$ \\
\hline $\begin{array}{l}\text { Had difficulty getting out } \\
\text { of bed in last month of life, } \\
\text { no. }(\%)\end{array}$ & $63(23.2)$ & $684(49.5)$ & $<0.001$ \\
\hline $\begin{array}{l}\text { Comorbidities, no. (\%) } \\
\text { Heart disease } \\
\text { Diabetes Mellitus } \\
\text { Lung disease } \\
\text { Stroke } \\
\text { Dementia } \\
\text { Cancer } \\
\end{array}$ & $\begin{array}{l}19(7.0) \\
18(6.6) \\
19(7.0) \\
22(8.1) \\
20(7.4) \\
38(14.0)\end{array}$ & $\begin{array}{l}151(10.9) \\
123(8.9) \\
130(9.4) \\
159(11.5) \\
165(11.9) \\
245(17.7)\end{array}$ & $\begin{array}{l}0.03 \\
0.11 \\
0.15 \\
0.25 \\
0.34 \\
0.04\end{array}$ \\
\hline
\end{tabular}

a. Where column total does not equal 100 , due to rounding differences 
Table 2. Associations Between Bereaved Family Member Perceptions of the Quality of Care and Presence of a Late Transition in the Last Three Days of Life

\begin{tabular}{|l|c|c|c|}
\hline \multicolumn{1}{|c|}{ Variable } & \multicolumn{2}{|c|}{ Frequency, \% (95\% Cl) } & $\begin{array}{c}\text { Adjusted } \\
\text { Odds Ratio }\end{array}$ \\
\hline & $\begin{array}{c}\text { Late Transition } \\
\mathrm{N}=272 \\
\text { (Weighted N = 1.0 million) }\end{array}$ & $\begin{array}{c}\text { No late transition } \\
\mathrm{N}=1381 \\
\text { (Weighted N = 5.0 million) }\end{array}$ & $\begin{array}{c}\text { Late transition } \\
(95 \% \mathrm{Cl})\end{array}$ \\
\hline Quality of care rated excellent & $43.6(37.2-50.2)$ & $48.2(44.9-51.0)$ & $0.79(0.58-1.06)$ \\
\hline $\begin{array}{l}\text { Unmet needs for pain } \\
\text { management }\end{array}$ & $27.5(20.6-35.7)$ & $21.4(18.5-24.7)$ & $1.20(0.74-1.94)$ \\
\hline $\begin{array}{l}\text { Unmet needs for dyspnea } \\
\text { management }\end{array}$ & $24.7(16.7-34.9)$ & $18.5(14.5-23.3)$ & $1.15(0.61-2.16)$ \\
\hline $\begin{array}{l}\text { Unmet needs for } \\
\text { anxiety/sadness management }\end{array}$ & $53.7(45.4-61.8)$ & $45.3(41.4-49.4)$ & $1.32(0.85-2.04)$ \\
\hline $\begin{array}{l}\text { Unmet needs for spiritual } \\
\text { support }\end{array}$ & $67.4(60.5-73.5)$ & $55.2(51.1-59.3)$ & $1.48(1.03-2.13)$ \\
\hline $\begin{array}{l}\text { Not always treated with } \\
\text { respect }\end{array}$ & $21.3(16.0-27.8)$ & $15.6(13.6-17.9)$ & $1.59(1.09-2.33)$ \\
\hline $\begin{array}{l}\text { Care not consistent with goals } \\
\text { (n) }\end{array}$ & $14.3(10.3-19.6)$ & $12.0(10.1-14.1)$ & $1.23(0.77-1.96)$ \\
\hline $\begin{array}{l}\text { Inadequate communication } \\
\text { about care decisions }\end{array}$ & $10.6(7.1-15.5)$ & $8.9(7.3-10.7)$ & $1.33(0.75-2.36)$ \\
\hline $\begin{array}{l}\text { Family not always kept } \\
\text { informed of patient condition }\end{array}$ & $31.0(24.3-38.6)$ & $20.9(18.7-23.2)$ & $1.54(1.07-2.23)$ \\
\hline
\end{tabular}

a. Adjusted for age, sex, race/ethnicity, comorbidities, relationship of proxy, and functional status.

Table 3. Adjusted Odds Ratios for Quality of Care Comparing Institution-toInstitution Late Transitions to No Late Transition

\begin{tabular}{|l|c|}
\hline \multicolumn{1}{|c|}{ Variable } & $\begin{array}{c}\text { Adjusted Odds Ratio } \\
\text { (95\%Cl) }\end{array}$ \\
\hline Quality of care rated excellent & $0.46(0.19-1.12)$ \\
\hline Unmet needs for pain management & $2.59(0.84-8.01)$ \\
\hline Unmet needs for dyspnea management & $1.15(0.26-5.05)$ \\
\hline Unmet needs for anxiety/sadness management & $3.66(1.34-10.02)$ \\
\hline Unmet needs for spiritual support & $1.02(0.35-2.97)$ \\
\hline Not always treated with respect & $2.06(0.69-6.17)$ \\
\hline Care not consistent with goals & $3.44(1.75-6.77)$ \\
\hline Inadequate communication about care decisions & $3.37(1.45-7.79)$ \\
\hline Family not kept informed of patient condition & $2.12(0.87-5.18)$ \\
\hline
\end{tabular}

${ }^{a}$ Adjusted for age, sex, race/ethnicity, comorbidities, relationship of proxy, and functional status. 


\section{Figure Legend}

Figure 1. Respondent Reports of Quality of Care by Whether Decedent Had No Late Transition, Any Late Transition or an Institution-to-Institution Late Transition

Legend: Height of bars is the proportion of respondents who had a positive answer for each quality of care measure on the x-axis. LT = late transition; $\mathrm{QOC}=$ quality of care.

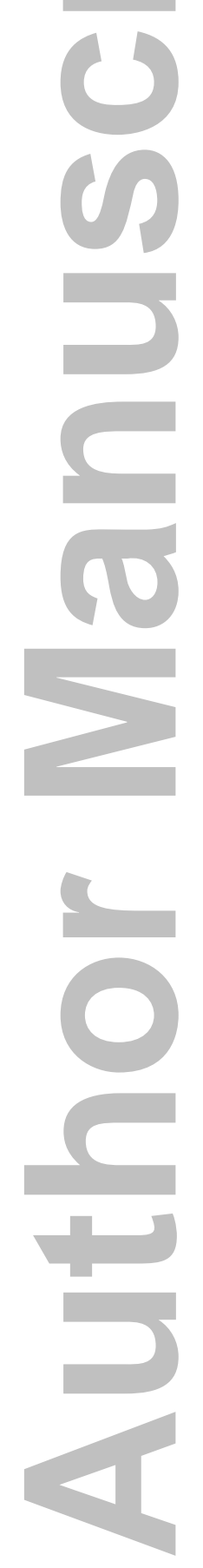


단

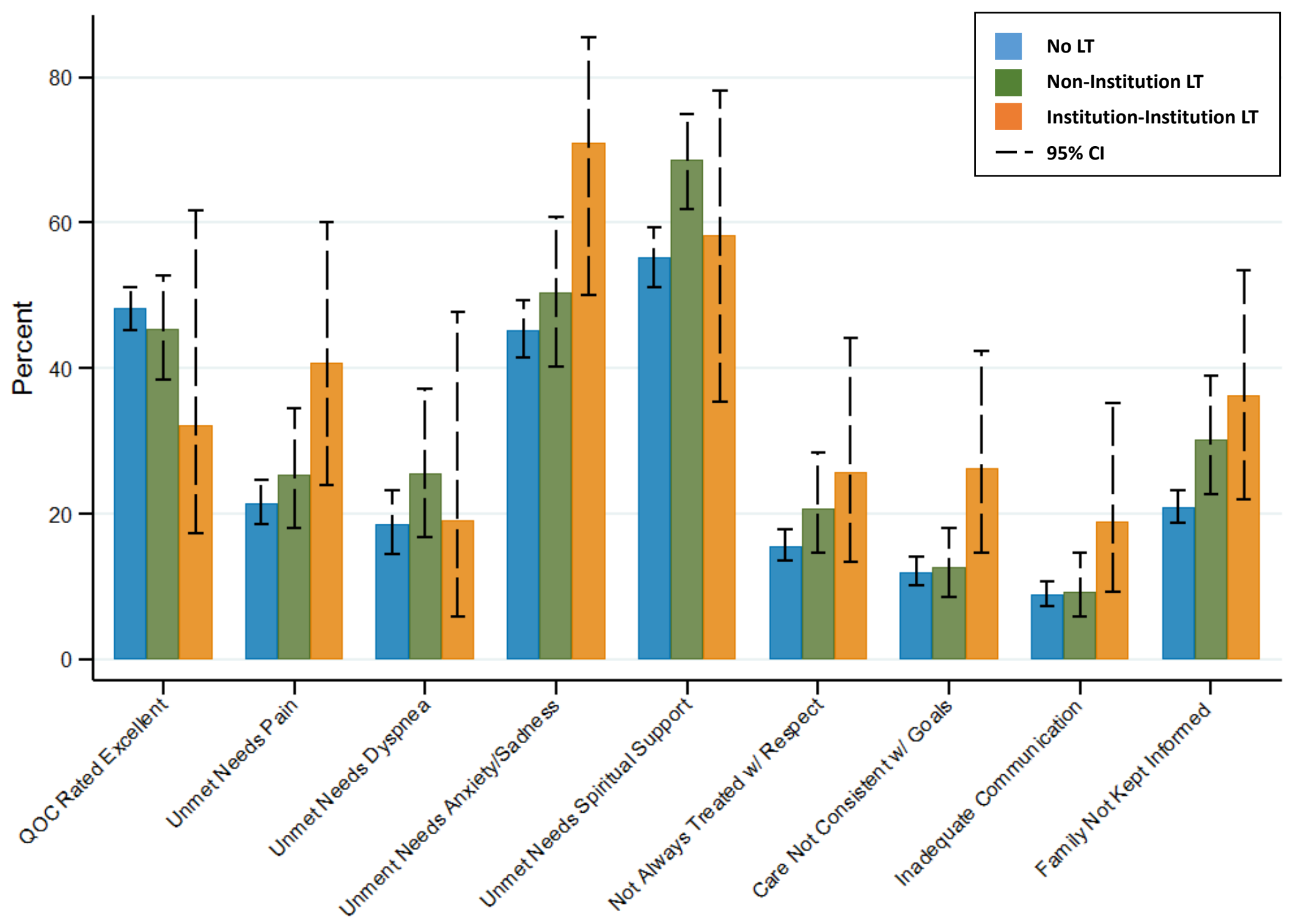




\section{Supplementary Appendix}

\begin{tabular}{|c|c|}
\hline Variable Short Name & NHATS LML Interview Question $^{\mathrm{a}}$ \\
\hline Quality of Care Rated Excellent & $\begin{array}{l}\text { Overall, how would rate }\{\text { SP\}'s care in the last month of life? } \\
\text { Would you say it was, excellent, very good, good, fair, or poor? }\end{array}$ \\
\hline Unmet Needs for Pain Management & $\begin{array}{l}\text { How much help in dealing with }\{\text { his/her }\} \text { pain did }\{S P\} \text { receive: } \\
\text { less than was needed, more than was needed, or about the } \\
\text { right amount? }\end{array}$ \\
\hline $\begin{array}{l}\text { Unmet Needs for Dyspnea } \\
\text { Management }\end{array}$ & $\begin{array}{l}\text { How much help in dealing with }\{\text { his/her }\} \text { breathing did }\{S P\} \\
\text { receive: less than was needed, more than was needed, or } \\
\text { about the right amount? }\end{array}$ \\
\hline $\begin{array}{l}\text { Unmet Needs for Anxiety/Sadness } \\
\text { Management }\end{array}$ & $\begin{array}{l}\text { How much help in dealing with [feelings of anxiety or sadness] } \\
\text { did }\{S P\} \text { receive: less than was needed, more than was } \\
\text { needed, or about the right amount? }\end{array}$ \\
\hline Unmet Needs for Spiritual Support & $\begin{array}{l}\text { During the last month of }\{\mathrm{SP}\} \text { 's life, do you think }\{\text { he/she }\} \text { had } \\
\text { as much contact [with doctors, nurses, or other health } \\
\text { professionals about }\{\text { his/her\} religious beliefs] as }\{\text { he/she }\} \\
\text { wanted? }\end{array}$ \\
\hline Not Always Treated with Respect & $\begin{array}{l}\text { During the last month of }\{\mathrm{SP}\} \text { 's life, how often were }\{\text { he/she\} } \\
\text { treated with respect by those who were taking care of } \\
\text { \{him/her\}: always, usually, sometimes, or never? }\end{array}$ \\
\hline Care Not Consistent with Goals & $\begin{array}{l}\text { During the last month of \{SP\}'s life, was there any decision } \\
\text { made about care or treatment that }\{\text { he/she\} would not have } \\
\text { wanted? }\end{array}$ \\
\hline $\begin{array}{l}\text { Inadequate Communication About } \\
\text { Care Decisions }\end{array}$ & $\begin{array}{l}\text { During the last month of }\{\mathrm{SP}\} \text { 's life, was there ever a decision } \\
\text { made about }\{\text { his/her\} care or treatment without enough input } \\
\text { from }\{\text { him/her\} or }\{\text { his/her\} family? }\end{array}$ \\
\hline $\begin{array}{l}\text { Family Not Always Kept Informed of } \\
\text { Patient Condition }\end{array}$ & $\begin{array}{l}\text { During the last month of }\{S P\} ' s \text { life, how often were you or other } \\
\text { family members kept informed about }\{\text { him/her\} condition: } \\
\text { always, usually, sometimes, or never? }\end{array}$ \\
\hline
\end{tabular}

a. For all questions regarding symptom management, the question was only asked if the respondent reported the presence of these symptoms in the last month of life.

Supplementary Table S2. Number and Proportion of All Late Transitions by Type

\begin{tabular}{|c|c|}
\hline Type of Late Transition & $\begin{array}{c}\text { Number (\%) } \\
\text { (total N = 283) }\end{array}$ \\
\hline Home to Hospital (including ICU) & $134(47.4)$ \\
\hline Home to Hospice Residence or Palliative Care Unit & $42(14.8)$ \\
\hline Hospital to Hospice Residence or Palliative Care Unit & $34(12.0)$ \\
\hline Nursing Home to Hospital & $26(9.2)$ \\
\hline Hospital to Nursing Home & $10(3.5)$ \\
\hline Nursing Home to Hospice Residence or Palliative Care Unit & $10(3.5)$ \\
\hline Home to Nursing Home & $5(1.8)$ \\
\hline Hospital to Other Hospital & $4(1.4)$ \\
\hline Hospice to any Other & $3(1.1)$ \\
\hline Other/Unknown to Any Location & $15(5.3)$ \\
\hline
\end{tabular}




\begin{tabular}{|c|c|c|c|}
\hline Variable & Frequency & $\%(95 \% \mathrm{Cl})$ & $\begin{array}{c}\text { Adjusted } \\
\text { Odds Ratio }^{\mathrm{a}}\end{array}$ \\
\hline 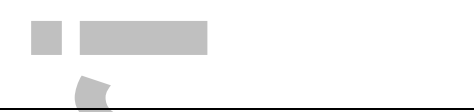 & $\begin{array}{c}\text { Late Transition } \\
\quad N=63 \\
\text { (Weighted } N=248,000)\end{array}$ & $\begin{array}{c}\text { No late transition } \\
\mathrm{N}=648 \\
\text { (Weighted } \mathrm{N}=2.4 \text { million) }\end{array}$ & $\begin{array}{l}\text { Late transition } \\
\qquad(95 \% \mathrm{Cl})\end{array}$ \\
\hline Quality of care rated excellent & $39.8(26.5-54.8)$ & $48.0(43.9-52.1)$ & $0.69(0.35-1.36)$ \\
\hline $\begin{array}{l}\text { Unmet needs for pain } \\
\text { management }\end{array}$ & $20.8(12.5-32.6)$ & $17.2(12.9-22.5)$ & $1.42(0.60-3.39)$ \\
\hline $\begin{array}{l}\text { Unmet needs for dyspnea } \\
\text { management }\end{array}$ & $12.0(5.9-22.8)$ & $14.4(10.4-19.5)$ & $0.84(0.26-2.73)$ \\
\hline $\begin{array}{l}\text { Unmet needs for } \\
\text { anxiety/sadness management }\end{array}$ & $56.8(39.7-72.4)$ & $37.0(30.8-43.6)$ & $2.66(1.15-6.15)^{*}$ \\
\hline $\begin{array}{l}\text { Unmet needs for spiritual } \\
\text { support }\end{array}$ & $56.7(40.4-71.6)$ & $49.5(43.3-55.7)$ & $1.83(0.90-3.71)$ \\
\hline $\begin{array}{l}\text { Not always treated with } \\
\text { respect }\end{array}$ & $20.1(10.5-35.1)$ & $13.7(11.0-17.0)$ & $1.93(0.79-4.70)$ \\
\hline Care not consistent with goals & $24.0(13.9-38.2)$ & $10.4(8.1-13.2)$ & $4.41(2.02-9.62)^{\star}$ \\
\hline $\begin{array}{l}\text { Inadequate communication } \\
\text { about care decisions }\end{array}$ & $26.6(16.6-39.8)$ & $9.1(6.8-11.9)$ & $4.37(2.18-8.79)^{*}$ \\
\hline $\begin{array}{l}\text { Family not always kept } \\
\text { informed of patient condition }\end{array}$ & $28.0(16.0-44.2)$ & $18.5(15.1-22.4)$ & $1.61(0.79-3.31)$ \\
\hline
\end{tabular}

a. Adjusted for age, sex, race/ethnicity, comorbidities and relationship of proxy.

\section{Supplementary Table S4. Associations Between Bereaved Family Member} Perceptions of the Quality of Care and Presence of a Late Transition in the Last Three Days of Life for Decedents with Respondents "Very Familiar" with Routine

\begin{tabular}{|l|c|c|c|}
\hline \multicolumn{1}{|c|}{ Variable } & \multicolumn{2}{|c|}{ Frequency, \% (95\% Cl) } & $\begin{array}{c}\text { Adjusted } \\
\text { Odds Ratio }\end{array}$ \\
\hline & $\begin{array}{c}\text { Late Transition } \\
\mathrm{N}=232 \\
\text { (Weighted N = 840,000) }\end{array}$ & $\begin{array}{c}\text { No late transition } \\
\mathrm{N}=1,142 \\
\text { (Weighted N = 4.2 million) }\end{array}$ & $\begin{array}{c}\text { Late transition } \\
(95 \% \mathrm{Cl})\end{array}$ \\
\hline Quality of care rated excellent & $48.9(41.0-56.8)$ & $50.6(47.3-53.9)$ & $0.88(0.62-1.25)$ \\
\hline $\begin{array}{l}\text { Unmet needs for pain } \\
\text { management }\end{array}$ & $27.6(20.0-36.9)$ & $20.2(17.3-23.5)$ & $1.27(0.79-2.04)$ \\
\hline $\begin{array}{l}\text { Unmet needs for dyspnea } \\
\text { management }\end{array}$ & $28.1(19.1-39.3)$ & $18.1(14.1-23.0)$ & $1.57(0.80-3.09)$ \\
\hline $\begin{array}{l}\text { Unmet needs for } \\
\text { anxiety/sadness management }\end{array}$ & $52.3(44.1-60.5)$ & $45.2(40.7-49.8)$ & $1.30(0.81-2.07)$ \\
\hline $\begin{array}{l}\text { Unmet needs for spiritual } \\
\text { support }\end{array}$ & $66.0(57.8-73.3)$ & $54.2(49.9-58.5)$ & $1.53(1.01-2.34)$ \\
\hline $\begin{array}{l}\text { Not always treated with } \\
\text { respect }\end{array}$ & $20.9(15.2-28.2)$ & $13.1(11.2-15.2)$ & $1.92(1.23-3.01)$ \\
\hline Care not consistent with goals & $15.8(11.0-22.2)$ & $12.9(10.6-15.5)$ & $1.26(0.74-2.13)$ \\
\hline $\begin{array}{l}\text { Inadequate communication } \\
\text { about care decisions }\end{array}$ & $10.0(6.3-15.5)$ & $8.9(7.2-11.0)$ & $1.33(0.68-2.59)$ \\
\hline $\begin{array}{l}\text { Family not always kept } \\
\text { informed of patient condition }\end{array}$ & $28.2(20.9-36.9)$ & $18.2(15.8-20.8)$ & $1.61(1.04-2.49)$ \\
\hline
\end{tabular}

a. Adjusted for age, sex, race/ethnicity, comorbidities, relationship of proxy, and functional status. 